\title{
Peritoneal Dialysis in a Patient with Neurogenic Bladder and Chronic Kidney Disease with Ventriculoperitoneal Shunt
}

\author{
M. Ram Prabahar M. Sivakumar V. Chandrasekaran E. Indhumathi \\ P. Soundararajan \\ Department of Nephrology, Sri Ramachandra Medical College, Sri Ramachandra University, Chennai, India
}

\section{Key Words}

Peritoneal dialysis $\cdot$ Neurogenic bladder .

Ventriculoperitoneal shunt

\begin{abstract}
Long-term dialysis in children with multiple handicaps has become easier with the advent of continuous ambulatory peritoneal dialysis (PD). Due to the widespread use of PD and the long survival of patients with spina bifida, an increasing number of patients with spina bifida are on PD. The viability and safety of PD in spina bifida patients with a ventriculoperitoneal shunt (VPS) have been a matter of concern. Some authors consider the presence of a VPS a relative contraindication for PD, but more recent reports suggest that PD under close monitoring is not contraindicated. We report a 17year-old girl born with meningomyelocele, hydrocephalus and neurogenic bladder who was maintained on VPS. She reached end-stage renal failure 17 years later and was put on PD based on family and patient preference. She had an uneventful course in the initial 9 months, but later developed fungal peritonitis which was successfully managed with catheter withdrawal and an intravenous antifungal agent (amphotercin $0.75 \mathrm{mg} / \mathrm{kg}$ ). Simultaneous ventricle-aspirated cerebrospinal fluid was sterile. To our knowledge, this is the first report of fungal infection in such a patient. Although we
\end{abstract}

share the view that PD is not an absolute contraindication in patients with a functioning VPS, its likely complications, especially infectious complications in developing countries, should be kept in mind before initiating PD in such patients.

Copyright ๑ 2008 S. Karger AG, Basel

\section{Background}

The choice of replacement therapy in children is variable. The registry of the North American Pediatric Renal Transplant Cooperative Study (NAPRTCS) has reported about patients initiating renal replacement therapy (RRT) in pediatric centers [1,2]: one quarter of the children underwent preemptive renal transplantation, one half were started on peritoneal dialysis (PD), and one quarter were started on hemodialysis. Thus, $\mathrm{PD}$ is the most commonly used mode of RRT in children.

When preemptive transplantation is not an option, the choice between the two forms of dialysis is generally dictated by technical, social, and compliance issues, as well as family preference. PD allows the least disruption of home life, school, and work attendance, when compared to hemodialysis which requires three weekly treatments of at least 3-4 h (not counting travel time). In addition,

\section{KARGER}

Fax +4161306 1234

E-Mail karger@karger.ch

www.karger.com
(C) 2008 S. Karger AG, Basel

0253-5068/08/0263-0274\$24.50/0

Accessible online at:

www.karger.com/bpu
Dr. M. Ram Prabahar

Department of Nephrology, Sri Ramachandra Medical College

Sri Ramachandra University, Chennai 116 (India)

Tel. +91 442476 5512, ext. 491, Fax +91 4424767008

E-Mail prabahar76@yahoo.co.in 
access to a nearby hemodialysis center may not be readily available to patients and their families. Long-term dialysis in children with multiple handicaps has become easier with the advent of continuous ambulatory peritoneal dialysis (CAPD).

Approximately $85-95 \%$ of patients with meningomyelocele have some degree of hydrocephalus, the pathogenesis of which has been a matter of speculation for a number of years and remains unclear. Blockade at the foramen magnum secondary to Arnold-Chiari malformation preventing access of cerebrospinal fluid (CSF) to the intracranial subarachnoid space has been stated to be the predominant cause. These patients usually have a ventriculoperitoneal shunt (VPS) for CSF diversion because the peritoneal cavity is the most common distal site for the placement of CSF shunts [3, 4]. Bowman et al. [4] found that $75 \%$ of patients with congenital spina bifida reached adulthood, and $86 \%$ had a CSF diversion. Endstage renal disease in these patients probably results from untreated recurrent pyelonephritis and bladder dysfunction. Due to the widespread use of PD and the long survival of patients with spina bifida, an increasing number of patients with spina bifida are on chronic PD. Although the viability and safety of $\mathrm{PD}$ in spina bifida patients with a VPS have been a matter of concern $[5,6]$, we could find only four references on concomitant VPS and PD in the literature [6-9]. Some authors consider the presence of a VPS a relative contraindication to PD because of the potential risks of shunt-induced peritoneal damage and ascending infection through the shunt $[10,12]$. However, based on a review of the literature, Warady et al. [6], Müller et al. [12] and Grünberg et al. [8,9] concluded that PD is not an absolute contraindication in patients with a functioning VPS and hence it should not be precluded.

We report a 17-year-old girl child born with meningomyelocele, hydrocephalus and neurogenic bladder maintained on VPS and clean intermittent catheterization. She reached end-stage renal failure 17 years later and was put on PD based on family and patient preference. She had an uneventful course in the initial 9 months, but later developed fungal peritonitis which was successfully managed with catheter withdrawal and an antifungal agent.

\section{Case Report}

A 17-year-old girl was referred to us with end-stage renal failure for RRT. Her problems started at birth after a full-term normal delivery. She was the child of non-consanguineous parents and the first of 3 siblings. At birth her neonatal physician noted a lump in

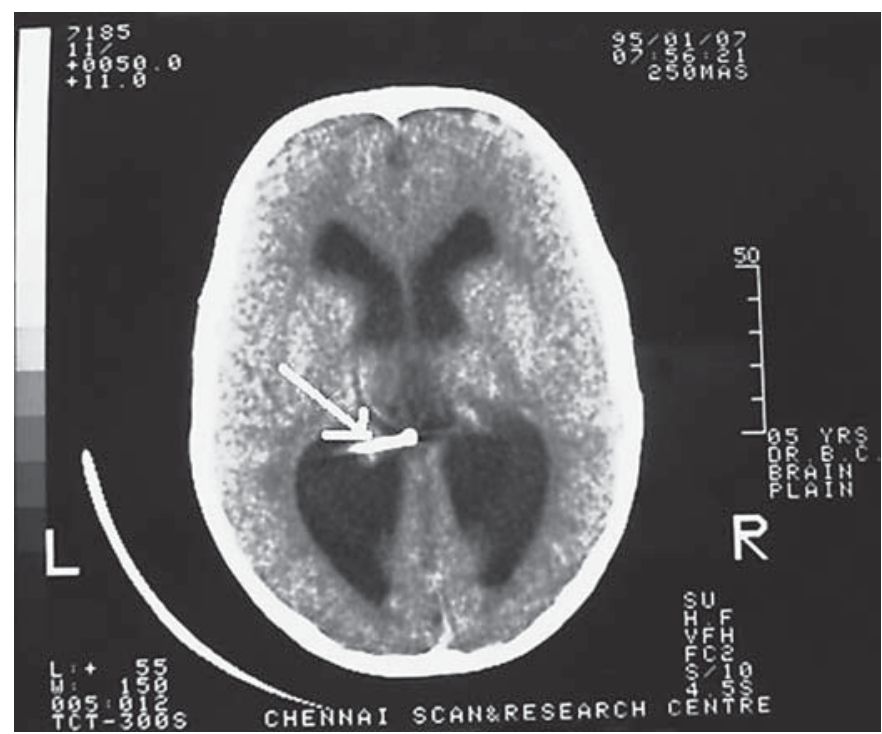

Fig. 1. Dilated ventricles with tip of VPS in situ (white arrow).

the lumbar region (meningomyelocele). She was referred to a neurosurgeon and underwent repair as a 3-day-old infant. The operative records available to us reveal that the patient underwent a five-layer closure of pia, arachnoid, dura, lumbodorsal fascia, subcutaneous tissue and skin. Three months later her parents noted the increasing head size, vomiting and incessant crying for which a CT scan was done that showed hydrocephalus. VPS was done using a Pudenz medium pressure tube (fig. 1). Subsequently, she had shunt dysfunction four times in the next 4 years and each time revision or lengthening of the VPS was done.

During the second revision surgery, she was found to have continuous dribbling of urine and positive urine culture. She was investigated. An ultrasonogram of the abdomen revealed bilateral hydroureteronephrosis. After being treated for a urinary infection, she underwent a micturating cystourethrogram which showed grade V reflux on both sides (fig. 2). DMSA scan showed bilateral cortical scars. Serum creatinine was $1.6 \mathrm{mg}$. A urodynamic study revealed detrusor areflexia and poor compliance bladder. Clean intermittent catheterization and antibiotic prophylaxis were advised.

She had repeated urinary tract infections (six times in the next 10 years) and was admitted and treated in various hospitals. She had a progressive rise in creatinine from 4 years of age and reached end-stage kidney failure at 17 years of age. At presentation to us she had stunted growth. Her mentation was normal. She had severe renal failure and uremic gastrointestinal symptoms. Serum creatinine was $7.2 \mathrm{mg}$. She had a residual urine output of 1 liter. The need for RRT was discussed with the family. The family appraised about the need for a bladder augmentation prior to transplant in consultation with a transplant surgeon. Since the family wanted time to decide about renal transplantation the dialytic modalities were discussed with them. The family and the girl opted for PD in view of convenience and least disruption of education. The risks of PD in presence of a VPS were explained to the family. After obtaining informed consent a peritoneal catheter 


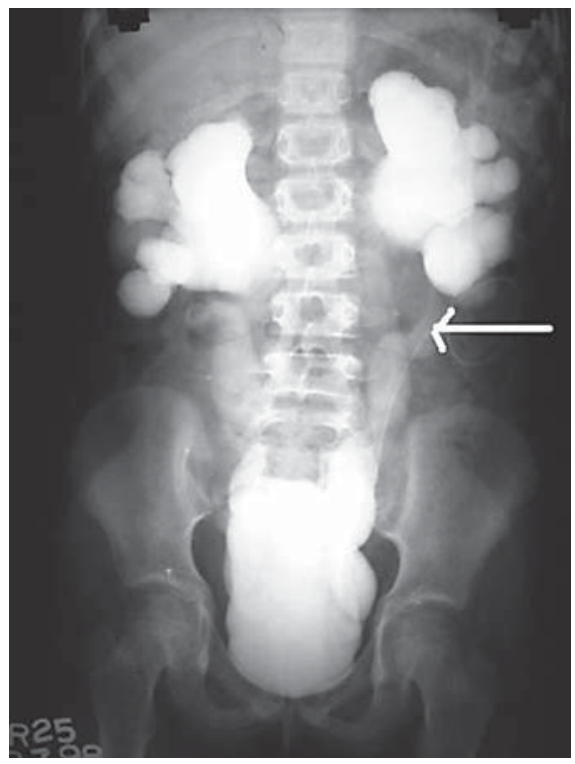

Fig. 2. Bilateral grade V reflux with VPS in situ (white arrow).

was inserted under aseptic precautions (fig. 3). Regular PD was initiated after a period of 2 weeks. The patient's baseline peritoneal equilibration test showed high average transporter status. The weekly Kt/V calculated was 2.02 and creatinine clearance was $62 \mathrm{l} /$ week.

She was on regular follow-up with an uneventful course for 9 months. The patient was admitted in the last month with abdominal pain and fever. Her peritoneal fluid cell count was 890 cells with predominant polymorphs (75\%). The fungal stain showed fungal elements. She did not have neck stiffness, meningeal signs or new neurological deficits. Guarded and guided CSF aspiration from ventricles was done with the help of a neurosurgeon and interventional radiologist. The fluid was clear and the pressure was normal. Biochemical studies revealed normal protein and elevated sugar. There were no cells. Simultaneously, PD fluid and CSF were sent for bacteriologic, tuberculous and fungal cultures. The catheter was removed and the tip was sent for culture. She was put on maintenance hemodialysis. The patient was started on intravenous amphotercin $0.75 \mathrm{mg} / \mathrm{kg}$ which was later continued for 3 weeks. The tip of the PD catheter and the PD fluid had grown Candida glabrata. The ventricle-aspirated CSF was sterile. The patient symptomatically improved within $48 \mathrm{~h}$; however, amphotercin was continued for 21 days.

To our knowledge this is the first report of fungal infection in such a patient. We reviewed the literature on CAPD in patients with VPS and only found four previous reports involving $9 \mathrm{pa}$ tients. In addition, we demonstrated that ascending infection is rare in such patients, and despite a fungal peritonitis episode our patient did not have fungal CNS infection. This patient is presented because of the rarity and also to emphasize the fact that VPS is no longer a contraindication to CAPD. However, its complications should be thoroughly discussed with the family, especially in developing countries where the chance of communityacquired infection is higher than in developed countries.

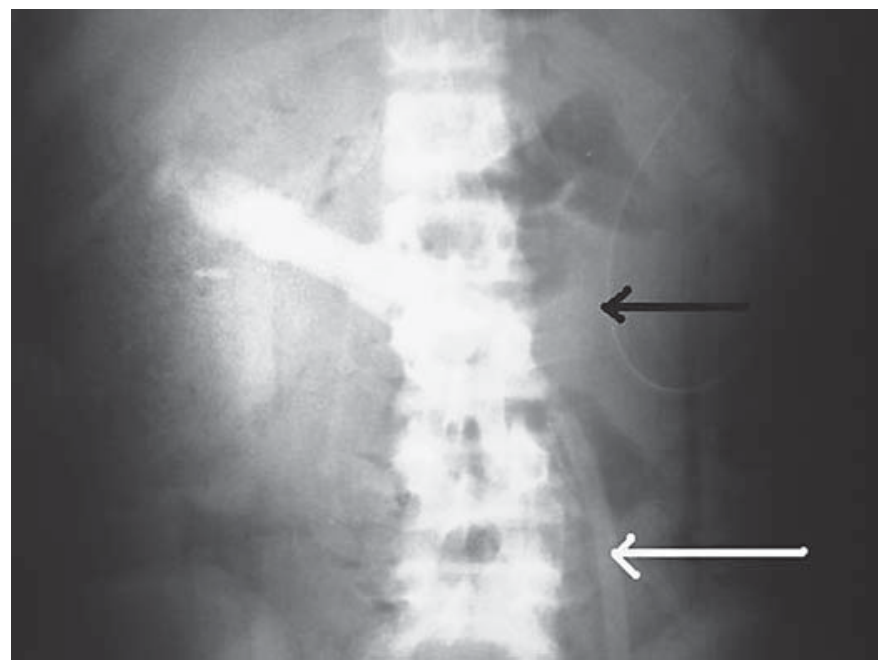

Fig. 3. Simultaneous presence of VPS (black arrow) and PD catheter (white arrow).

\section{Discussion}

Neurogenic bladder is considered a major risk factor for chronic pyelonephritis and progressive renal damage in children $[12,13]$. PD is the main modality of RRT in children. Most patients have associated VPS for CSF drainage. The presence of VPS makes PD more complicated in these patients. Previously it was generally thought that the presence of VPS is a contraindication for PD [10, 12], but more recent reports suggest that PD under close monitoring is not contraindicated in children with meningomyelocele regardless of the presence of VPS or any other stoma $[6,8,9,11]$.

The peritoneal cavity is crucial for children with spina bifida since it is the most common distal site for spinal shunt placement as well as for PD [9]. Some doubts have been raised about PD safety and feasibility in patients with spina bifida with concomitant PD catheter and VPS. Those concerns are the risk of ascending infection secondary to peritonitis, long-term peritoneal membrane damage due to CSF and long-term patient and PD catheter survival $[6,12]$.

Infections in either the ventricular or peritoneal cavities could lead to a secondary spread to the other compartments via VPS connection. Retrograde brain ventricular infection secondary to peritonitis via VPS can occur. Fortunately the present shunt catheter design allows CSF to flow one way only, avoiding reflux into ventricles [9]. However, theoretically the spread of infection can still 
occur via the pericatheter route. Peritonitis has been reported by several authors $[6,7,14]$ not to cause ascending infection; however, there is a single report of shunt infection without ventriculitis in a patient with peritonitis who responded to treatment with continuation of both modalities [14]. Despite a fungal peritonitis episode in our patient too, there was no spread of infection to the ventricles.

The second issue in PD patients with VPS is the potential increased risk of loss of peritoneal membrane function secondary to chronic CSF exposure. The CSF secretion rate is approximately $750 \mathrm{ml} /$ day in adults and somewhat less in children [15]. Based on a sample of 4 patients, Grünberg et al. [8] showed that there was no increase in intraperitoneal hydrostatic pressure, fill volume intolerance (pain, discomfort) or interference to flow of CSF through VPS. The upper level of intra-abdominal pressure reported was $\leq 12 \mathrm{~cm} \mathrm{H}_{2} \mathrm{O}$ in patients with concomitant PD and VPS. The authors hypothesize that CSF fluid load is tolerated well in children with VPS and PD due to time-acquired tolerance. However, massive right hydrothorax in one patient with concomitant VPS and PD has been reported by Grünberg et al. [8]. On investigation there was no evidence of ventriculitis, peritonitis, or impairment of VPS drainage. This episode of hydrothorax was hypothetically related to an increase in intraperitoneal hydrostatic pressure and/or pleuroperitoneal communication. The patient was advised PD with small exchange volumes in the sitting position. It is not routinely recommended to switch the VPS to another site like atrium or to the pleural cavity before initiating PD. No reports are available on long-term extraperitoneal sites for CSF diversion in children on PD.

Regarding the long-term outcome of $\mathrm{PD}$, Grünberg et al. [9] analyzed patient and technique survival and peri- tonitis in patients with spina bifida and those without spina bifida, but were unable to find any statistically significant differences. Ascites and sclerosing encapsulated peritonitis secondary to VPS may develop several months or even years after the placement of VPS even without PD [16-19]. In patients with long-standing VPS without PD, peritoneal biopsies have demonstrated that ascites is of peritoneal origin. Sterile ascites secondary to silicone in VPS has been reported by Longstreth and Buckwalter [20]. Endothelial injury as suggested by Milton et al. [21] may be yet another mechanism of VPS-induced peritoneal membrane damage. As of now, no data are available to determine whether PD solution and CSF are synergistic or additive factors in the development of peritoneal damage. Hence it is recommended that PD patients with VPS require periodic evaluation of ultrafiltration.

Spina bifida patients on PD present specific diagnostic challenges due to overlapping symptoms secondary to PD (vomiting, fever, abdominal pain) or VPS-related complications (visceral injury due to devices or primary disease (pyelonephritis)) with inherent risks of delaying adequate treatment. Cloudy peritoneal effluent is an early indication of peritonitis; however, it is not specific [8]. Both early diagnosis and management of complications require appropriate knowledge and skills on the part of the physician and a coordinated approach with the pediatric surgeon, neurosurgeon, urologist and nephrologist. The exact source of peritonitis is difficult to determine in patients with VPS on PD.

We conclude that CAPD is no longer a contraindication in patients with a functioning VPS and hence should not be precluded. However, physicians, patients and parents need to be forewarned about possible complications, especially in developing countries, for early diagnosis of complications in order to minimize potential risks.

\section{References}

1 Seikaly M, Ho PL, Emmett L, Tejani A: The 12th Annual Report of the North American Pediatric Renal Transplant Cooperative Study: renal transplantation from 1987 through 1998. Pediatr Transplant 2001;5: 215-231.

$\checkmark 2$ Neu AM, Ho PL, McDonald RA, Warady BA: Chronic dialysis in children and adolescents. The 2001 NAPRTCS Annual Report. Pediatr Nephrol 2002;17:656-663.

$\checkmark 3$ Vernet O, Rilliet B: Late complications of ventriculoatrial or ventriculoperitoneal shunts. Lancet 2001;358:1569-1570.
4 Bowman RM, McLone DG, Grant JA, Tomita T, Ito JA: Spina bifida outcome: a 25-year prospective. Pediatr Neurosurg 2001;34: 114-120

$\checkmark 5$ Fine RN: Ask the expert. Pediatr Nephrol 1989;3:316.

-6 Warady BA, Hellerstein S, Alon U: Advisability of initiating chronic peritoneal dialysis in the presence of a ventriculoperitoneal shunt. Pediatr Nephrol 1990;4:96.

$\checkmark 7$ Kazee MR, Jackson EC, Jenkins RD: Management of a child on CAPD with a ventriculoperitoneal shunt. Adv Perit Dial 1990;6: 281-282.
8 Grünberg J, Rébori A, Verocay MC: Peritoneal dialysis in children with spina bifida and ventriculoperitoneal shunt: one center's experience and review of the literature. Perit Dial Int 2003;23:481-486.

9 Grünberg J, Verocay MC, Rébori A, Pouso J: Comparison of chronic peritoneal dialysis outcomes in children with and without spina bifida. Pediatr Nephrol 2007;22:573-577.

10 Shetty A, Oreopoulos DG: Peritoneal dialysis: its indications and contraindications. Dial Transplant 2000;29:71-77. 
-11 Kawaguchi Y, Kawanishi H, Mujai S, Topley N, Oreopoulos DG: Encapsulating peritoneal sclerosis: definition, etiology, diagnosis, and treatment. Perit Dial Int 2000;20(suppl 4):S43-S55.

12 Müller T, Arbeiter K, Aufricht C: Renal function in meningomyelocele: risk factors, chronic renal failure, renal replacement therapy and transplantation. Curr Opin Urol 2002; 12:479-484.

13 Brown S, Marshall D, Patterson D, Cunningham AM: Chronic pyelonephritis in association with neuropathic bladder. Eur J Pediatr Surg 1999;9(suppl 1):29-30.
4 Jameela K: Neuropathic bladder as a cause of chronic renal failure in children in developing countries. Pediatr Nephrol 2006;21:517520.

15 Swaiman KE: Spinal fluid examination; in Swaiman KE, Ashwal S (eds): Pediatric Neurology: Principles and Practice, ed 3. St Louis, Mosby, 1999, pp 115-121.

16 Chidambaram B, Balasubramanian V: CSF ascites: a rare complication of ventriculoperitoneal surgery. Neurol India 2000;48: 378-380.

17 LaFerla G, McColl KE, Crean GP: CSF-induced sclerosing peritonitis: a new entity? $\mathrm{Br}$ J Surg 1986;73:7.
8 Yukinaka M, Nomura M, Mitani T, Kondo Y, Tabata T, Nakaya Y, et al: Cerebrospinal ascites developed three years after ventriculoperitoneal shunting in a hydrocephalic patient. Intern Med 1998;37:638-641.

19 Yount RA, Glazier MC, Mealey J Jr, Kalsbeck JE: Cerebrospinal fluid ascites complicating ventriculoperitoneal shunting. Report of four cases. J Neurosurg 1984;61:180-183.

20 Longstreth GF, Buckwalter NR: Sterile cerebrospinal fluid ascites and chronic peritonitis. N Engl J Med 2001;345:297-298.

21 Milton CA, Sanders P, Steele PM: Late cardiopulmonary complication of ventriculoatrial shunt. Lancet 2001;358:1608. 